\title{
OUT OF THE BOX: SOUTHWARDS AND EASTWARDS NOTES ON A NEW GEOGRAPHY OF CRITICISM
}

\author{
A B S T R A C T
}

Viewed from the "Southern Europe", the theoretical/critical debate in the Anglo-Saxon world, in particular the ongoing debate at the American universities is perplexing. It is a world of opulence and loftiness, not in this case on the level of material wealth, but intellectual wealth. If we understand that the omnipresence of "critical theory" has an inhibitive effect on a sensory relationship with architecture, and that dichotomies such as critical/projective are schematic, the truth is that we need to leave behind atavisms that diminish the approach in "Southern Europe": the local against the global; the space against the images; the young against the old.

Theory and criticism have much to gain from allowing themselves to be provoked by the unknown. I would like to concretise these ideas by revisiting two recent experiences: to the South, Cape Verde, and to the East, Macau. They are border situations of wealth and material prosperity in Macau; and of poverty and obstruction in Cape Verde. How are these territories read and criticised? The architecture we find there is outside the history based on the MoMA. In China one hears the echo of echoes, increasingly. In Africa, one can hear the distant resonance of those echoes. Where are we beyond "post-criticism". 


\section{CRITICAL / PROJECTIVE}

Viewed from the now famous "Southern Europe", the theoretical/critical debate in the Anglo-Saxon world, in particular the ongoing debate at the American universities, does not cease to amaze. Although one cannot deny it has certain charms and must acknowledge the mastery with which it is conducted, the image of a gigantic bubble about to burst nevertheless comes to mind.

I speak from a place at the European periphery that is in the throes of a crisis. Almost surreally, given the current context, a Portuguese architect, Eduardo Souto de Moura, was awarded the Pritzker Prize this year. This is an example of the decentralisation of the recognition of merit made possible by post-modernity. Nevertheless, thanks to the ongoing crisis, the trend today would seem to be towards regrouping of the "centre" as the dominant, hegemonic power.

I will be speaking from the viewpoint of a particular geo-culture, at a time in which the former sea routes of the Portuguese discoveries towards the South and the East gave us a certain comfort when faced with Europe that is divided, when it is not threatening. Our proximity to Africa, particularly the Africa in which the joys and sufferings of life are experienced by the Portuguese and the Creole, makes everything more relative. For this reason I will be speaking of Cape Verde, to the South, and Macau, to the East, with relish in this real and symbolic decentralisation.

But, first, let us return to the "centre".

The theoretical language of the American universities - I use this term to simplify things - is distanced, abstract, sculpted from philosophical citation and immersed in "critical theory". For these reasons it is alienated from the sensibility of this somewhat imagined "Southern Europe", which, again thanks to the crisis, sometimes also includes Ireland.

Here I, appositely, make reference to the famous text by Robert Somol and Sarah Whiting, "Notes around the Doppler Effect and other Moods of Modernism", which caused such an uproar and was identified as marking the emergence of "post-criticism". It proposes moving from a "critical" approach, which, according to these authors, is based on the work of K. Michael Hays and Peter Eisenman - who had Colin Rowe and Manfredo Tafuri as their mentors - to a "projective" and interdisciplinary approach, where Rem Koolhaas emerges 
as an example. This concept of "post-criticism" unleashed countless reactions. The most notorious is perhaps the one resulting from a seminar that was held at the Bartlett School of Architecture in 2004 and published in Critical Architecture $^{2}$, where the theme was debated in great detail and the arguments of Somol and Whiting were vehemently rejected. In the introduction to the book, Jane Rendell, one of the editors, reiterates the need for a "critical" approach: "with respect to the current debate concerning post-criticism, I strongly argue for the possibility of criticism and design as vital forms of intellectual and creative labour, which aim to lay bare social, cultural and ethical concerns at the heart of contemporary aesthetic and spatial practice"3.

Somol and Whiting's text features the habitual philosophical references and nods to popular culture. The parallels drawn between the performances of Robert de Niro as a representative of the "critical" faction (also described as "hot", "difficult") and that of Robert Mitchum as representing the new "projective" (or "cool", "easy") faction, perhaps marks the zenith of American theory: it is witty; it hits the mark. But one must ask: what is going on here?

Perhaps one could argue that the complex configuration of Eisenman's City of Culture in Santiago de Compostela is "hot", particularly considering the scandal it has generated. And, indeed, we can walk through the Casa da Música in Porto, or the McCormick Tribune Campus Center at the Illinois Institute of Technology in Chicago - referenced apropos this question by David Cunningham $^{4}$ - and feel the presence of a certain coolness. Though it is true that Koolhaas, like David Byrne, only manages to be really cool after a lot of physical effort that wears the intellect out. (And that indeed is postmodernism: the exact moment of the passage from cerebral to chill-out, from intellectualism to the dance floor).

But, as I was saying, in the "Southern European" context, the division between the critical, validated by the "disciplinary autonomy" of architecture, and the projective, validated by interdisciplinarity, does not make much sense. "Disciplinary autonomy" is always being contested by reality. Architecture is thought and lived with a "critical" objective, in accordance with a logic of "interdisciplinarity". It is a sensitive and beautiful battle between an impossible object ("autonomy") and a slippery object ("interdisciplinarity").

"Disciplinary autonomy" descends from Boullée's "exalted rationalism", a concept with which Aldo Rossi wanted to capture architecture. In its further evolution, this "autonomy" is understood as a poetic desire and not a place 
that one can or should really occupy. But, either by greed or luxury, theory in American universities cultivates a world that is coded, corseted, with its own obligatory gurus, outside the sensory pleasure. Manfred Tafuri, in particular, is a figure that constantly re-emerges. We cannot blame Tafuri for this, but he has created an industry of the "death of architecture" that has served, with highs and lows, for all types of theoretical vampirism. As Joan Ockman has written, there was a fatal encounter in the mid-70s between the vanguards of Venice and New York that filled a vacuum in America ${ }^{5}$. One could say that the American universities need the most radical European gurus - Tafuri and, later, Jacques Derrida - to avidly fill the historical void in matters of architectural theory.

In the criticism of modern architecture - which, as understood by him, operates essentially in the field of representations - Tafuri eliminated any possibility of architecture playing a revolutionary role that would be destined for it in a Marxist perspective. From this it follows, in the Tafurian approach, that architecture feeds only itself and off itself; or that it is a headless animal running around in perpetual agony. This pessimistic reading, based on denunciation and "unmasking", means a loss of contact with the sensory, as Ignasi de SolàMorales noted in his day: "Tafuri, indeed, disqualifies from his intellectualism every experience whose object is sensory pleasure, as if that purpose, inherent in the art of all times, were the quintessence of a hedonism denounced a hundred times over in Tafuri's texts as the most negative of faults"'. At the centre of that hedonism it is difficult not to see the American experience of the world. However, in an extraordinary twist, as Solà-Morales writes, "those who willingly accept this radical criticism, who suffer it and stimulate it, are precisely those who are its objects"'. The disqualification, in the end analysis, of the very experience of architecture, this hegemony of intellectualism is transferred to the American context, against all evidences. The recurrent return to Tafuri, despite all the initial doubts and subsequent misunderstandings, as Diane Ghirardo describes in an implacable reading of the relationship between Tafuri and America ${ }^{8}$, is the greatest example of intellectual masochism one can imagine. For Tafuri, writes Solà-Morales, "theoretical work" provides "points of support for a denunciation, a permanent action of unmasking capable of evaporating any announcement of synthesis, values, innovation or progress that does not include class struggles" $"$. This Marxist character is eclipsed in American theses. Eisenman's known political alienation perhaps helps to explain that circumstance. Perhaps, there is also a great degree of cynicism: what is of interest is the validation of Venice, the Old World, regardless of what it costs and what it says. 
With the decline of the "grey" filiation and after post-modernism, American pop sensibility surrendered the driver's seat to deconstructivism, with new highways in the horizon. The realism and humour of the pop tradition were a hyper-real vision of America, in which the grotesque became transparent more than the refined. The radical adoption of philosophical, Marxist and then deconstructivist readings is perhaps a sign of the guilty conscience for the strictly pragmatic understanding that architecture occupies in the course of American history. Given this appetite for theory, fidelity to texts and subtexts tends to be irrelevant. The gurus are pawns to that voracity. However, it is Europe that counts, in the tradition of the "whites" against the more engrained American visions of the "greys".

In this sense, "post-criticism" is one more chapter in that saga, a generational change that perpetuates the presence of Tafuri as the big bang of theory in America. Solà-Morales asks the question: "was Manfredo Tafuri interested in contemporary architecture?"10. American universities think he was, and they have cultivated that certainty ever since, regardless of the will of the person concerned.

\section{LEAVING ATAVISMS BEHIND}

Without wanting to enter into anti-Americanism, which I generally avoid, the sensation we have in the middle of this story is that of a world of opulence and loftiness, not in this case on the level of material wealth, but intellectual wealth. A world drawn retrospectively on the basis of the incredible collection of the MoMA, where the modern European experience, even the best documented, is reproduced as a "local", i.e. American, experience. A locality that becomes confounded with the home address of globalisation: 11 West 53rd Street, Manhattan. Look at the recent example, Modernist America by Richard Pells ${ }^{11}$, which treats the heroic experiments of Central Europe in the 1920s as food for the construction of modernism in America.

As Peter Sloterdijk writes, America, the land of post-history, now wants to be a part of history ${ }^{12}$, even if it has to rewrite it for that purpose. Which calls for this degree of intellectual violence, or gratuity exemplified where Tafuri is concerned.

To use a trendy term, one could say that there is a certain fatness in this approach, in its opulence and opacity. And that the built architecture always seems to fall short of the grand designs of the theoretical writings. In calmer 
times, the deconstructivist game of performing the criticism within the system, the idea of squeezing the jugular veins of corporations without shock surprises - beyond the zigzagged walls and slanted roofs - had a certain glamour to it and was intellectually chic. But, as Kim Dovey writes, things are looking less that way now: "many of the products of deconstruction can now be seen as little more than stylistic effects that reframe and reproduce the very social relations they were conceived to resist"13. Pure hatred for certain starchitects has thrown the love-hate relationship that has always existed off balance. The "autonomy" of much of that architecture came to be emblematic of a selfsufficient and arrogant fatness. Crisis tends to intensify the bombastic and not the critical subtleties. See the case of the City of Culture in Santiago de Compostela: of what interest are theories of overlapping and interaction of solid and void spaces when the whole thing is a white elephant? Even if it is unfair to attribute the megalomania of the project solely to the architecture only, the truth is that the architecture cannot be dissociated from the whole madness of the undertaking. It is the channel through which the megalomania is expressed.

Indeed, it is an interesting exercise to plot a Galician-Portuguese itinerary from Frank Gehry's Guggenheim in Bilbao, to the City of Culture in Santiago and the Casa da Música in Porto. It allows one to follow the critical/projective debate and draw one's own political conclusions. All three works have escaped strict rationality and are the result of more generous times. Gehry's post-modernism, in trash-pop mode, still reflects a certain festiveness and has managed to escape, in the meantime, a darker destiny, even if it does look like a circus with imported clowns.

The City of Culture, which reflects the whimsical vision of the President of Galicia, Manuel Fraga Iribarne, is inscribed in the "critical" assumption: it is architecture in love with itself, with its imminent critical effect. It is also known as "Fraga's Mausoleum". It is not exactly the most appropriate architecture for this period of frugality. From which one can conclude that, just as implementing democracy is no easy thing in the Middle East, deconstructivist architecture cannot easily or self-evidently be exported to "Southern Europe".

The Casa da Música, on the other hand, is cool. It is "projective architecture", "atmospheric" and "diagrammatic", as recommended by Somol and Whiting. And it has been quite a success. But it is interesting to note how, in Critical Architecture, Koolhaas emerges sometimes as being part of the "critical" equation ${ }^{14}$, when others place him in the "projective" category ${ }^{15}$. 
As I said, however, the political deceleration that presupposes "post-criticism" seems to be in a counter-cycle, as has been underlined repeatedly in Critical Architecture. On the contrary, the correlation among architecture and the political and the social is on the agenda. But one needs to know the exact terms of that relationship in order to find a theoretical and critical operability that seems to escape us. Because, even if a certain degree of self-satisfaction and distancing from the practice are patent, the innovative character and editorial and academic efficiency of American theoretical output cannot be denied. If we understand that the omnipresence of "critical theory" has an inhibitive effect on a sensory relationship with architecture, and that dichotomies such as critical/ projective are schematic, the truth is that we need to leave behind the atavisms that diminish the approach in "Southern Europe". In the part of Europe that is more immune to the Anglo-Saxon world in particular it is necessary to redefine concepts, to have greater critical lucidity and a more attuned language. I will give three examples. They all derive from the European genealogy of modern architecture, from that loyalty to the various branches that developed over the $20^{\text {th }}$ century. Now, in the most conservative fashion, they awake notions of authenticity and "resistance" that weigh a lot in cultural terms: the local against the global; the space against the images; the young against the old.

Indeed, globalisation is not the opposite of locality. On the contrary, globalisation feeds off a radicalised performable locality. Globalisation is a thick fog looking for beacons. All fogs need beacons. The beacons are the localities that rise up and are able to operate in the midst of the fog, pointing the way. This is the case in the work of Peter Zumthor, or that of Souto de Moura. Globalisation needs the local like Coca Cola needs Pepsi or the Empire State Building needs the Chrysler Building. The global is that which is organic, flies over things, and has a penchant for kitsch; or for the parochial, as Sloterdijk explains ${ }^{16}$. In order to get out of this paradoxically small rota de mundo, the global needs an operative locality: an invented or hyperbolised tradition, as is the case in Zumthor and Souto de Moura. The local cannot be pitched against the global, for that would be like trying to kill a vampire with blood.

Another of the conventions that impedes a more radical and critical conscience of architecture is the importance given to space, which is clearly a modernist leftover. Against the "images". The space's turn as leading actor in architecture ended in 1972 with Learning from Las Vegas ${ }^{17}$. But even architecture that is most loyal to the modern tradition reveals itself in its unrepentant visuality. The architecture of Souto de Moura has always been very visual, i.e. very much interested in the composition as it is to the gaze, more than as it is to the body, in the manner of Mies van der Rohe. 
Traditionally, photographs were understood as a two-dimensionalisation of space, with a degree of loss. Now we can say that space is a threedimensionalisation of the recurrent and viral images of each building. The prevalence of the gaze, or the visual, over the body or the spatial does not mean that the space is not important in architecture. It means that it is no longer the "protagonist", to return to an old term used by Bruno Zevi. The experience of space is a luxury that many times escapes the flow of the consumption of architecture as a cultural product. There is a set of elements - images, texts, gossip - that impose themselves upon the experience of the space of a building. These elements are not necessarily "succedaneous" to the work; it is the work that can be seen as "succedaneous" to the set of operations that mediatized it. Architecture can exist in the form of rumour; the rumour would be the protagonist of architecture today.

Finally, the apologia of the "young" in architecture reflects the encounter between the vanguard culture of Europe in the 1920s and the cult of youth culture that flourished in America in the 1950s. The need to innovate and renew generations is healthy. And it is apparently a nice thing - though less so in the "killing of the father" version, an act that will be increasingly more difficult because the "fathers" are in hypertext.

The thing is that in Europe there are no young people. We are European; we are not young. Our baggage is heavy. Which is why Koolhaas swam in the "Floating Pool" with the constructivist architects/lifeguards to New York in the 1970s and is now flying to China. China, India, Brazil are young. Africa is young; tragically so, if we look for the average life expectancy. All the youth is in those cultures, along with the corresponding drawbacks and incapacities: the lack of own space; the passing crises; the servitude to tutorship or the rebellions without a nexus. We are the older brothers or cousins. There is nothing worse than seniors who still think they are "young". For this reason, the European architectural programme, our medicine - after the juvenile madness of the museums and the stadiums - is, naturally, rehabilitation.

\section{TO THE SOUTH AND TO THE EAST}

The most important conquest of post-modernity, and indeed it has value in terms of civilisational advancement and is still ongoing, is that of ending centralising or dominating models. I fear, as I said in the beginning, that the current crisis will lead to the return of crude shows of strength by the strongest. But the possible destruction of absolutist models allows peripheral or small regions and minority or "independent" groups to have a voice without the 
old constraints. The "centre" itself has, in this post-modernity now in danger, greater plasticity, a desire to share and a greater aesthetic openness. As we have seen, globalisation needs locality. From a decentralised space new, more ample, personal and real experiences can emerge. Theory and criticism have much to gain from allowing themselves to be provoked by the unknown.

I would like to concretise this idea by revisiting two recent experiences: one in Macau, where I was the "scientific coordinator" for the film Learning from Macau, on the work of Manuel Vicente, an architect of the Portuguese Diaspora, directed by José Maçãs de Carvalho. And the other in the island nation of Cape Verde, in the context of the ongoing research into the architectural output of the Portuguese Colonial Planning Office, which is being coordinated by Ana Vaz Milheiro. I will not go into the contents of these two projects but will look at what they have enabled me to see.

They are border situations, of wealth and material prosperity in Macau; and of poverty and obstruction in Cape Verde. They are both proud small territories. Macau is experiencing urban change at a vertiginous rate in a very short period of time; in Cape Verde one senses expectation and being in it for the long haul. Both situations elude the critical paraphernalia of the Anglo-Saxon world. How are these territories read and criticised? The architecture we find there is outside the history based on the MoMA. But one feels its vibrations, remotely: through the colonial power in the colonial period; and through China, tortuously, in this global period. China is also in Cape Verde.

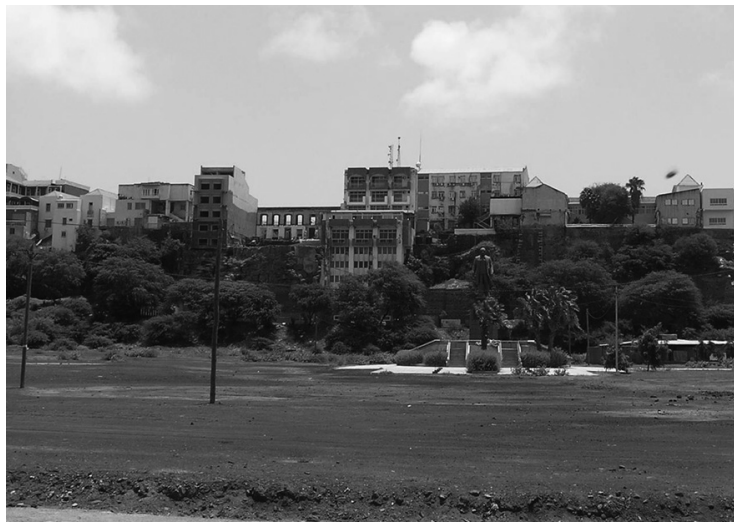

Figure 1 Platô - exterior view, Santiago, Cape Verde (Photo by Jorge Figueira)

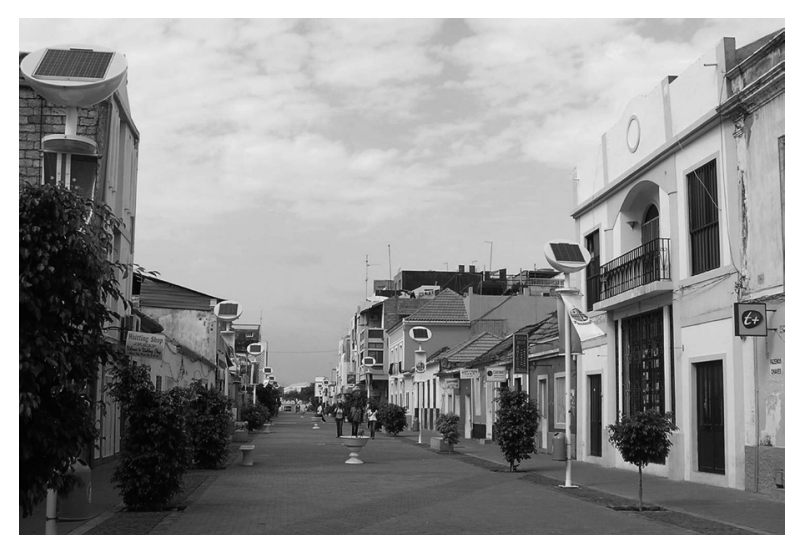

Figure 2 Platô - interior view, Santiago, Cape Verde (Photo by Jorge Figueira) 
They are, in both cases, experiences in a globalised world. I do not want to speak from an ethnic or exotic viewpoint. The critical approach that is my point of departure is as explained above: an admirer and critic of the Anglo-Saxon model; testing the hypothesis of "Southern Europe" as a sensory and plastic space. This is a challenge for me. I am speaking from a difficult position: that of the ex-discoverer and ex-coloniser, retracing an impossible course, bigger than life, that takes the Portuguese from Cidade Velha in Cape Verde to Macau in the Far East.

Macau was under Portuguese administration until 1999. It was the last European colony in China. Now it is a Special Administrative Region of the People's Republic of China. Cape Verde was one of Portugal's "overseas provinces" in Africa (along with Angola, Mozambique, Guinea Bissau and São Tomé and Príncipe) up until 1975.

Over the course of time Macau has built itself up as a meeting place between "East and West", with gambling, which was prohibited in China, defining the prosperity of that destiny. This has resulted in an improbable mixture of topographic wisdom and controlled scale that is Portuguese in origin, the Chinese types - the patioed house, the temple - and the gaming typologies: the "moneylender towers", the pawn shops, the hotels and casinos. This very particular balance was altered by the liberalisation of gambling following the transfer of Macau to China. The confrontation between the intimacy of the Macau urbanity and the emergence of the "Cotai Strip" - Cotai is a contraction

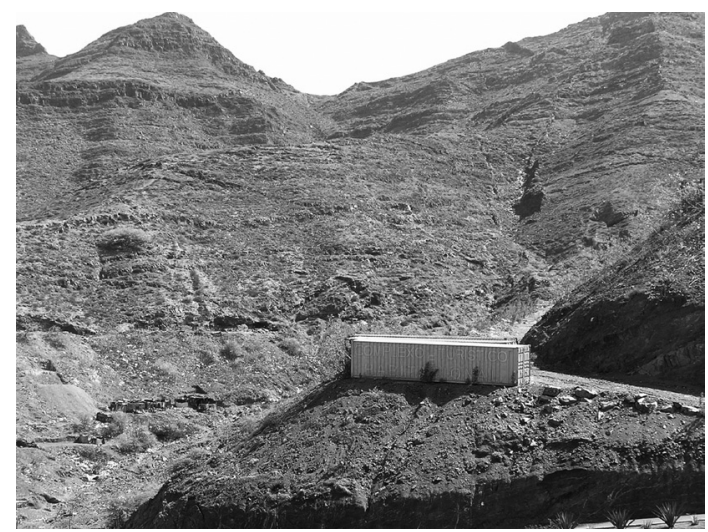


of the words Coloane and Taipa, two islands in Macau - as in Las Vegas Strip, has replaced the prior "east-west" tension. Macau has now outstripped Las Vegas in terms of gaming revenue.

From the point of view of criticism it is interesting to follow the architectural dispute between the Asian casinos and those of American origin. Take, for example, the Galaxy Macau, which opened this year and is an American design - by the Los Angeles-based firm of Gary Goddard - but aspires to recreating the Asian world. On the purely American side, if one can put it in those terms, the Venetian Macau, completed in 2007, proposes an upgrade of the habitual replicas: the Grand Canal Shoppes has 330 stores and offers "authentic gondola trips". The gondolas are real but Venice emerges in a somewhat improved form. This "Canal Grande" does not smell of Venice but of McDonalds. It is America under our feet even if we are in China. Forget about Venice; the Venetian Macau is an improved replica of the Venetian in Las Vegas.

The Grand Lisboa, opened in 2007, is the response to the liberalisation of the market in 2001 by Stanley Ho, the central figure in the Macau gaming world. It is located next to the pre-existing, and now somewhat quaint looking Casino Lisboa, which opened in the early 1970s in Baía da Praia Grande. The gigantism of Grand Lisboa is patent: it can be seen from everywhere. The base is a blown-up balloon on which 1.2 million LEDs constantly change colour; the stem, apparently inspired by the Lotus bloom, a symbol of Macau, can be likened to a fettered body; the head is small. It looks like an out-ofproportion Robocop.

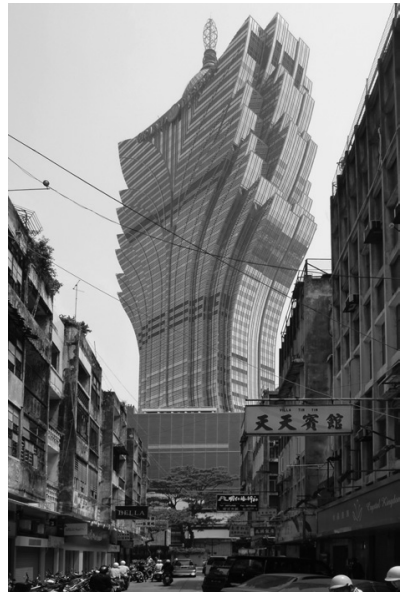

Figure 4 Grand Lisboa exterior view (Photo by Jorge Figueira)

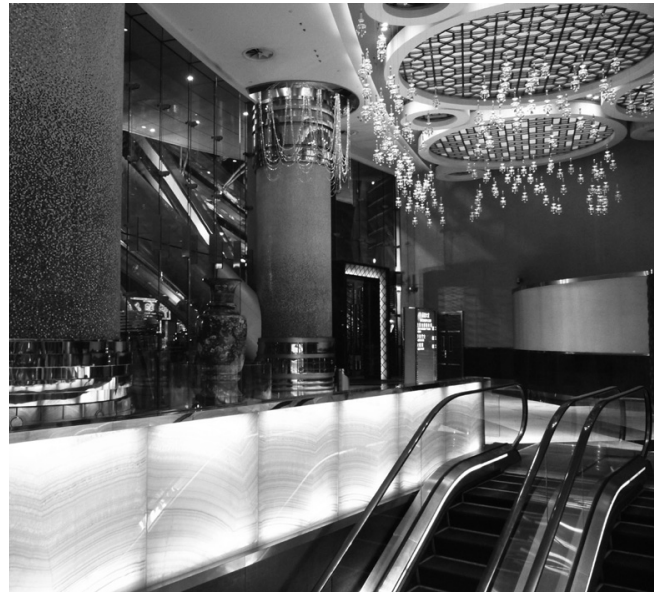

Figure 5 Grand Lisboa interior view (Photo by Jorge Figueira)

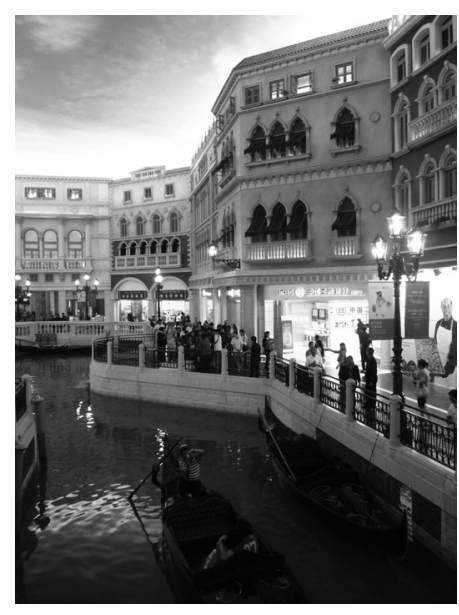

Figure 6 Venetian Macao interior view (Photo by Jorge Figueira) 
But it is the Grand Lisboa interior that is truly unsettling. Here one can find and experience all the luxury that China has to offer. It is pure spatial, decorative and formal acceleration - no mediation, no project. Contrary to the American casinos, this one does not have a legible narrative or "signature". It does not have a fiction, beyond the expedient Lotus flower. It has extraordinary chandeliers; thousands of aluminium bits. It is a skyscraper full of sophisticated knick-knacks.

In this orgy of materials it is, however, more "authentic" - and certainly more "local" - than the American casinos. But in what terms is it more "authentic"? It does not rely on Venice (as the Venetian does) or Lisbon (as the MGM next door does). While in the American casinos there is a preoccupation to present the luxury through a culture or city, in the Grand Lisboa what we see is abstract art. It is not even the triumph of the replica that is valid in China in general. Here is a voracity in the direction of nothing. Or of thousands of shiny lights. The passage from figurative art to abstract art, just like in the avantgarde movements in the early $20^{\text {th }}$ century.

In the city of Praia on the island of Santiago in Cape Verde there is a magnificent place: the Platô (derived from the word "plateau"). The Platô is a kind of acropolis that structures the whole historic city of Praia linearly. The recent urban planning has, quite rightly, sought to find infrastructures and facilities appropriate for the adjacent areas, the diverse plateaus where the city has developed in recent decades. But the geographic delimitation of the Platô, its formal composition and the parochialism of its palatial and religious location lend it the unique character of an imagined, unreal city. The Platô is an exciting small city, a cultural displacement undisturbed in land that is at times arid and inhospitable, and at times very green and humane. It is an endangered oasis of everyday, modern and traditional architecture; with a light density in plazas and squares lived on a daily basis. Where the sublime music of Cape Verde can be heard in the late afternoon and at night. Where is the Platô headed? In the adjacent Várzea valley, cooperation with the Chinese has led to the building of the public library and more buildings have been planned. A Macau casino opens its doors on the "Cotai Strip" and diverse buildings emerge in Africa.

The houses in the more privileged neighbourhoods of Praia show a formal excess and a wealth of finishes that tells us we are in the capital of Cape Verde. In other parts of the city and on other islands of the archipelago - in the city of Mindelo on São Vicente or in Porto Novo on Santo Antão - the new houses are more eccentric, accelerated, at times strangely, in the nihilist direction of the 
architecture of the Asian casinos. They are difficult to read, and very difficult to love. The desire is there, but not the rule; a world in transformation, without preparation. Or perhaps a paradigm that we have not yet identified.

What Cape Verde or Macau do not have, what is not permitted by the velocity of the wealth and the inertia of poverty, is an architecture of mediation mainstream and popular but qualified. Architecture that interprets and makes the connections, that establishes a "locality" as mentioned in the preceding section. And theory and criticism that monitors it and gives it meaning. In Macau, the residential buildings are gigantic structures with windows like holes, which are filled by the so-called "cages" that seek to soften them. The new single-family homes in Mindelo are caricature - like sketches of a culture that escapes them. They are - in a brutally distinct way - forsaken, needy spaces. Cape Verde suffers on the blind side of globalisation; Macau is blinded by the lights of globalisation.

Understanding the Grand Lisboa and reading the Platô call for a new availability of criticism. In China one hears the echo of echoes, increasingly. In Africa, one can hear the distant resonance of those echoes. The "Cotai Strip" is on an obvious slope downwards towards organised, big-spending madness. I would like to think that the Platô also has the right to be seen as an exciting place. Two places waiting for criticism. Perhaps it is time we got out of the cafés where, as George Steiner so brilliantly wrote ${ }^{18}$, Europe was made, and headed south and east. Where we are beyond "post-criticism". 
Robert Somol and Sarah Whiting. "Notes around the Doppler Effect and other Moods of Modernism" in Mining Autonomy, Perspecta 33 (2002): 72-77. Architecture, edited by Jane Rendell, Jonathan Hill, Murray Fraser and Mark Dorrian (London and New York: Routledge, 2008 [2007]), 7. Rendell, Jonathan Hill, Murray Fraser and Mark Dorrian (London and New York: Routledge, 2008 [2007]), 37. Joan Ockman, "Venezia e New York.” Casabella. 619-620 (1995):57.

6 Ignasi de Solà-Morales "Más allá de la crítica radical. Manfredo Tafuri y la arquitectura contemporánea" [2000] in Inscripciones, (Barcelona: Gustavo Gili, 2003), 252. Ibid.251.

Diane Y. Ghirardo, "Manfredo Tafuri and Architecture Theory in the U.S., 1970-2000" Perspecta 33 (2002): 38-47.

9 Solà-Morales, Más allá de la crítica radical. Manfredo Tafuri y la arquitectura contemporánea, 
257.

Ibid. 245 .

Richard Pells, Modernist America. Art, Music, Movies and the Globalitazion of American Culture. New Haven and London: Yale University Press, 2011.

Peter Sloterdijk, Palácio de Cristal. Para Uma Teoria Filosófica da Globalizaçã (Lisbon: Relógio d'Água, 2008 [2005]), 250-253.

Kim Dovey, "I Mean to be Critical, But..." in Critical Architecture, edited by Jane Rendell, Jonathan Hill, Murray Fraser and Mark Dorrian (London and New York: Routledge, 2008 [2007]), 253.

Murray Fraser, "Beyond Koolhaas" in Critical Architecture, edited by Jane Rendell, Jonathan Hill, Murray Fraser and Mark Dorrian (London and New York: Routledge, 2008 [2007]), 332.

Jianfei Zhu, "China as a Global Site" in Critical Architecture, edited by Jane Rendell, Jonathan Hill, Murray Fraser and Mark Dorrian (London and New York: Routledge, 2008 [2007]), 302.

Solà-Morales, Más allá de la crítica radical. Manfredo Tafuri y la arquitectura contemporánea, 274-278.

Robert Venturi, Izenour, Steven Brown and Scott Denise. Learning from Las Vegas. Revised Edition, (Cambridge, London: The MIT Press, 1998 [1972]).

George Steiner, A Ideia de Europa (Lisbon: Gradiva, 2005), 26.

Cunningham, David "Architecture as Critical Knowledge" in Critical Architecture, edited by Jane Rendell, Jonathan Hill, Murray Fraser and Mark Dorrian, 31-39. London and New York: Routledge, 2008 [2007].

Ghirardo, Diane Y. "Manfredo Tafuri and Architecture Theory in the U.S., 1970-2000" Perspecta 33 (2002): 38-47.

Dovey, Kim. "I Mean to be Critical, But..." in Critical Architecture, edited by Jane Rendell, Jonathan Hill, Murray Fraser and Mark Dorrian, , p. .252-260. London and New York: Routledge, 2008 [2007].

Fraser, Murray. "Beyond Koolhaas" in Critical Architecture, edited by Jane Rendell, Jonathan Hill, Murray Fraser and Mark Dorrian, p.332-339. London and New York: Routledge, 2008 [2007].

Ockman, Joan. "Venezia e New York." Casabella. 619-620 (1995):56-71.

Pells, Richard. Modernist America. Art, Music, Movies and the Globalitazion of American Culture. New Haven and London: Yale University Press, 2011.

Rendell, Jane. "Introduction. Critical architecture: between criticism and design" in Critical Architecture, edited by Jane Rendell, Jonathan Hill, Murray Fraser and Mark Dorrian, p.1-8. 
London and New York: Routledge, 2008 [2007].

Sloterdijk, Peter. Palácio de Cristal. Para Uma Teoria Filosófica da Globalização. Lisbon: Relógio d'Água, 2008 [2005].

Solà-Morales, Ignasi de."Más allá de la crítica radical. Manfredo Tafuri y la arquitectura contemporánea" [2000] in Inscripciones, Barcelona: Gustavo Gili, 2003, p.243-253

Somol, Robert and Sarah Whiting. "Notes around the Doppler Effect and other Moods of Modernism" in Mining Autonomy, Perspecta 33 (2002): 72-77.

Steiner, George. A Ideia de Europa. Lisbon: Gradiva, 2005.

Venturi, Robert, Izenour, Steven Brown and Scott Denise. Learning from Las Vegas. Revised Edition, Cambridge, London: The MIT Press, 1998 [1972]

Zhu, Jianfei. "China as a Global Site" in Critical Architecture, edited by Jane Rendell, Jonathan Hill, Murray Fraser and Mark Dorrian, p.301-308. London and New York: Routledge, 2008 [2007]. 